\title{
Study on the design and execution of a short fiber reinforced polyamide part
}

\author{
Vlad Bocăneț ${ }^{1,}$, Adrian Popescu $^{1}$, Cristina Fenișer $^{1}$ and Iulian Tamba ${ }^{1}$ \\ ${ }^{1}$ Technical University of Cluj-Napoca, Machine Building Faculty, Bvd. Muncii 103-105, Romania
}

\begin{abstract}
This article presents the stages and problems that can arise from the design to the realization of a part obtained through the process of injection. The model part used in the research is a part used in the automotive industry made on a large scale. The material from which the workpiece is made is a polymer that is part of the Polyamide class namely Polyamide 6.6 armed with short fiberglass (SGFR-PA 6.6). The fiberglass arming was made at a $30 \%$ rate, resulting in a significant increase in the mechanical characteristics of the workpiece. The validation of the flow in the injection mold was done using Moldflow Adviser ${ }^{\mathrm{TM}}$. Due to the contraction of the material, different problems of the injected parts may occur, which endanger their proper functioning. Measurements were done by using a GOM ATOSTM optical scanner. The scanned part was compared with the CAD model and the deviations were observed.
\end{abstract}

\section{Introduction}

Todays manufacturing processes are rapidly evolving. As new equipment, methods and materials appear, manufacturers need to adapt and adopt these new elements in order for them to stay competitive. That is why they must understand their manufacturing processes from the design to the implementation stage. Each step is critical in the successful release of a part or product. That is why materials need to be tested, designs perfected and processes simulated. Composite materials are widely used because of their high strength to weight ratio and resistance [1]

The mold injection process is quite complex. There are multiple parameters that need to be considered during the three-stage process: filling, packing/holding and cooling [2]. These parameters are dependent upon temperature, pressure, crystallinity and compressibility of the material [2].

After the part has been molded, other components are assembled on it. The assembly is either done manually or automatically. Because of the complexity of molded parts used in the automotive industry, most of the time the assembly process is manual.

The workpart used in the study is part of the seat actuator assembly of a car. After the plastic part is molded, electronics are manually mounted. The most important parts of this assembly, from a quality point of view are the 7 pins that are part of the socket (Figure 1).

\footnotetext{
* Corresponding author: vlad.bocanet@tcm.utcluj.ro
} 
The analysis of the manufacturing process starts with the material analysis followed by the flow analysis and quality control.

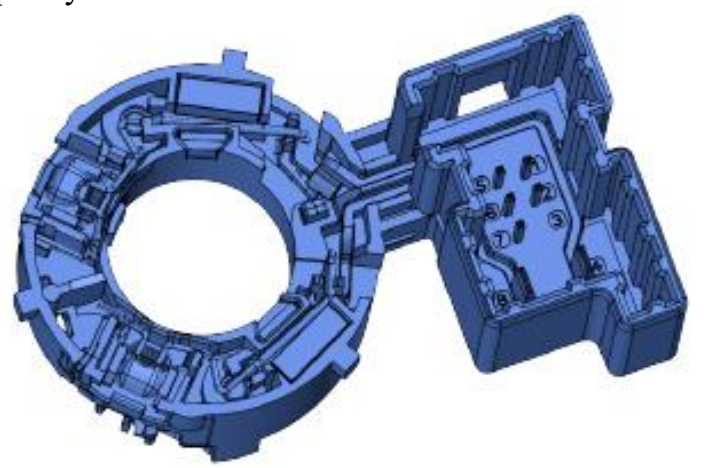

Fig 1. The studied part

\section{Determination of fiber direction within the material}

Currently, the polymeric materials with short fibers are used on a large scale in the automotive industry and beyond. The arming with various organic or inorganic compounds makes the resulting products: cheaper, biodegradable or with, better mechanical characteristics, depending on the type and functional role of the finished product. In order to improve the mechanical characteristics of parts others have used glass fibers [2-4].

The mechanical properties of short fiber reinforced polyamide (SFRP) depend on fiber content, fiber dimensions and fiber orientation distributions [5].

In the present paper by the arming of polyamide 6.6 with $30 \%$ short glass fiber an improvement of the mechanical characteristics of the resulting piece is intended. This is imposed by the functional role of the part.

The distribution of the reinforcement fibers has an important role on the mechanical resistance of the stecher and has been researched by others as well [6-9]. The technological parameters of injection are set to optimum value, thus resulting in parts of an appropriate quality. Fibers tend to orient themselves in the flow direction of the polymer melt. The more the degree of reinforcement increases the fibers collide with each other and deviate from this rule, distributing themselves randomly.
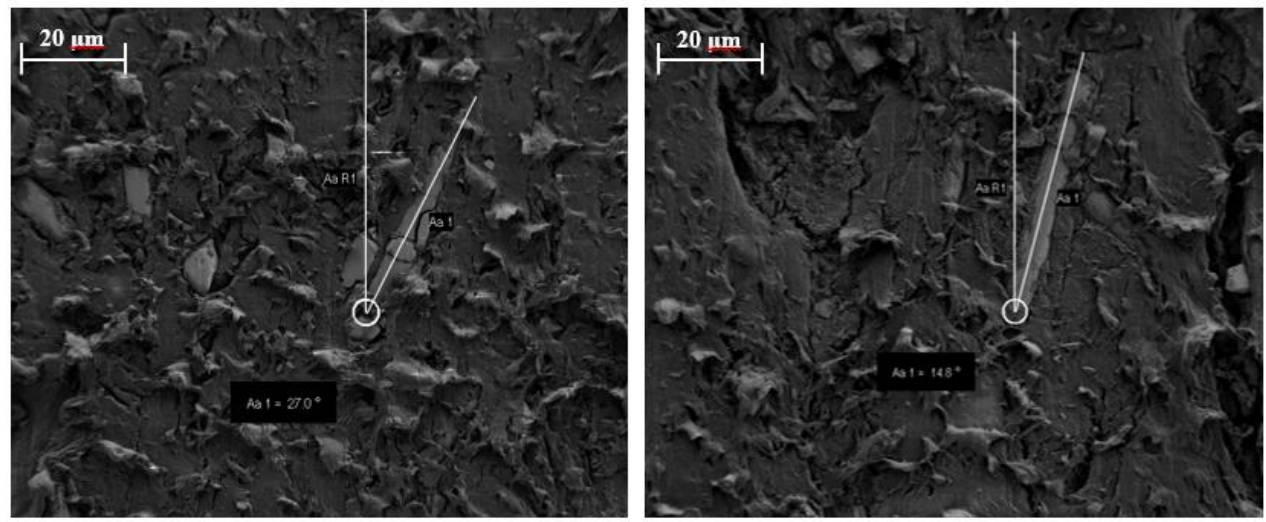

Fig 2. Orientation of reinforcement fibers on the surface of the workpiece in SGFR-PA $6.630 \mathrm{wt} . \%$ 
By doing a Scanning Electron Microscopy (SEM) analysis, an uneven dispersion of glass fibers can be observed. The higher the degree of reinforcement the more the angle of orientation of the fibers towards the flow direction differs, some fibers reaching even perpendicular orientation to the direction of flow (Figure 2).

For better highlighting of the orientation of the reinforcement fibers, SEM analysis was made in the breaking area of the test parts (Figure 3). An important role in the mechanical resistance is the adhesion of fiber in the polymer material. In Figure 3, a good enrolling of the reinforcement material in the polymer material can be observed.

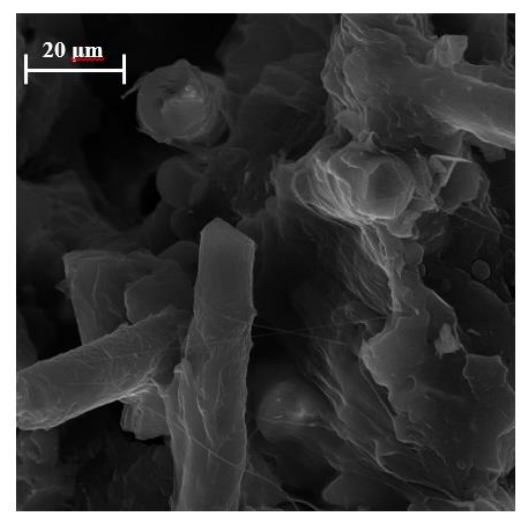

Fig 3. Orientation of reinforcement fibers in the rupture of the SGFR-PA $6.630 \mathrm{wt} \%$ specimen

The different orientation of the reinforcement fibers constitutes an advantage because the workpiece can take strains within the limits of the mechanical resistance throughout its surface.

\section{Flow analysis}

The last stage before the design of the injection mold is to make a flow analysis of the used material. For this we used Moldflow Adviser ${ }^{\mathrm{TM}}$. Following this analysis, important values are obtained with which the injection process can be optimized. For example, you can find the exact amount of time required to keep the workpiece until it is extracted. Depending on this value it is decided whether the mold needs to be fitted with a cooling circuit. The time to reach ejection temperature in this case was 13.2 seconds (Figure 4) meaning that it does not require additional cooling.

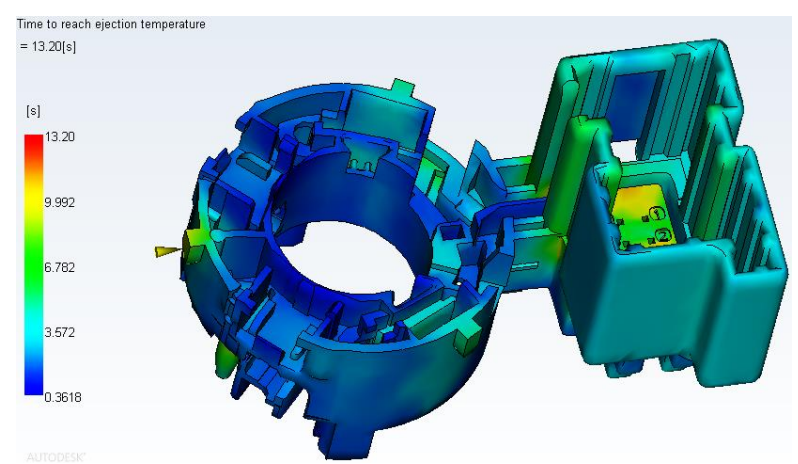

Fig. 4. Time to reach ejection temperature of the piece 
The variation in temperature and injection pressure may be highlighted during the process (Figure 5).
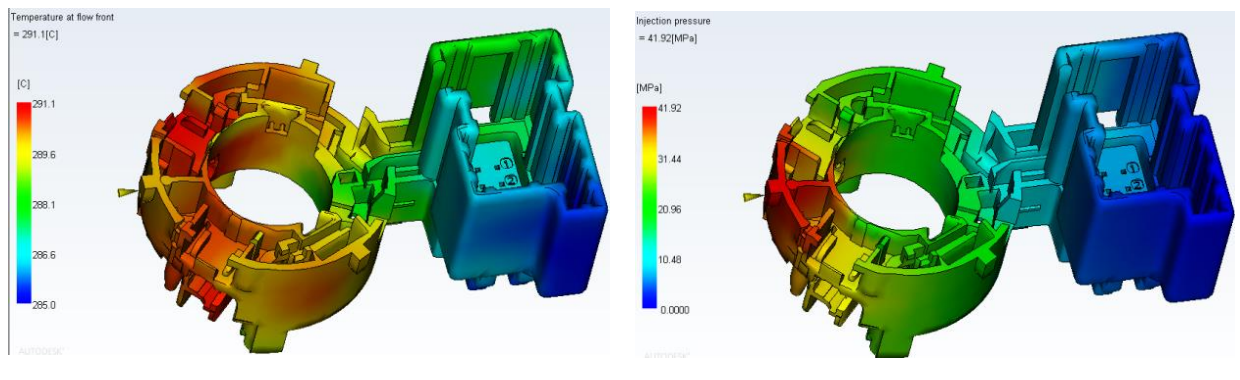

Fig. 5. Temperature at flow front and injection pressure

We can also determine if the obtained piece has certain defects, such as air traps, if there are problems filling the nest and there is also a "Quality prediction" feature for the mold (Figure 6)

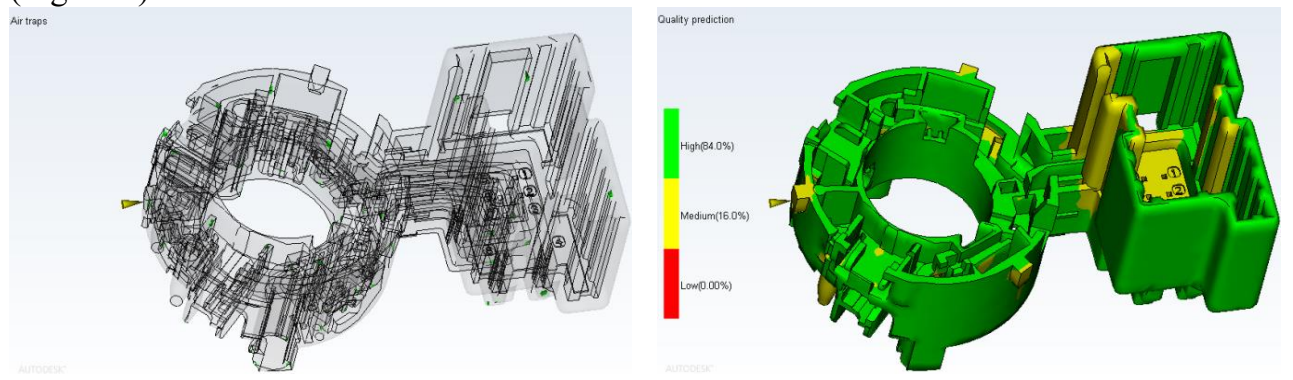

Fig. 6. Air Traps and Quality Prediction

All these results provide very useful information for the correct and at the same time economic design of the injected mold.

\section{Inspection of the part}

To fulfill its intended design purpose, the part needs to be compliant not only from a material point of view but also from a dimensional point of view. The critical dimensional elements for this part are in the socked area. There are 7 pins that need to correctly assemble with a plug. The pins are made of brass and are manually inserted into the molded part (Figure 7). The manufacturer allowed a $0.1 \mathrm{~mm}$ deviation in the position of the pins.

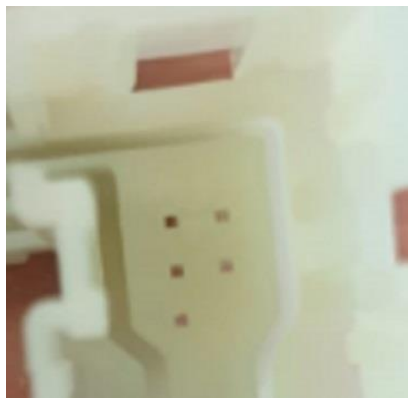

Fig. 7. The socket area before the manual assembly of the metallic pins 
Three parts were inspected by using a GOM ATOS ${ }^{\mathrm{TM}}$ optical scanner. This is a stereoscopic optical scanner that uses a blue light fringe pattern projector to digitize parts with a maximum resolution of $0.03 \mathrm{~mm}$. The resulting point cloud is then used to create a mesh that can be aligned and compared to a CAD model of the part. This is done by using GOM Inspect TM (Figure 8).

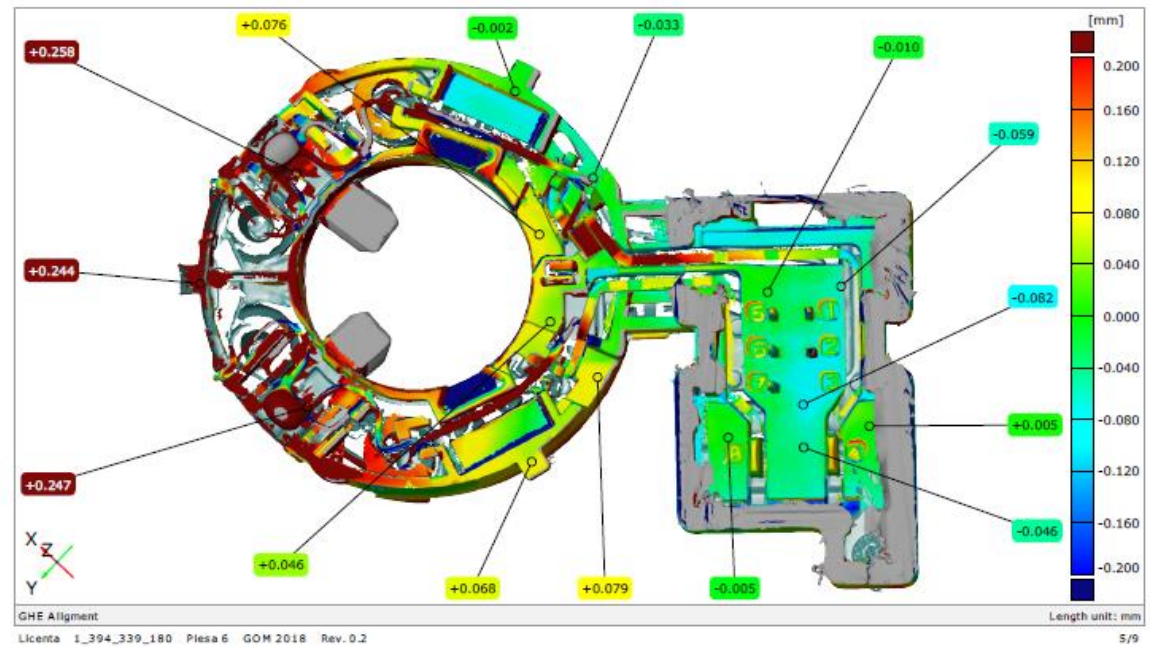

Fig. 8. Deviations between the Mesh and the CAD model for one of the tested parts

Of all the three parts that were scanned all had out of tolerance deviations for at least one pin (Figure 9). The sources of deviations that were identified were:

- the injection molding process resulting in wrong position of the holes where the pins would be mounted;

- the incorrect mounting of the pins as this is a manual process;

- the pins themselves if they are not correctly executed.
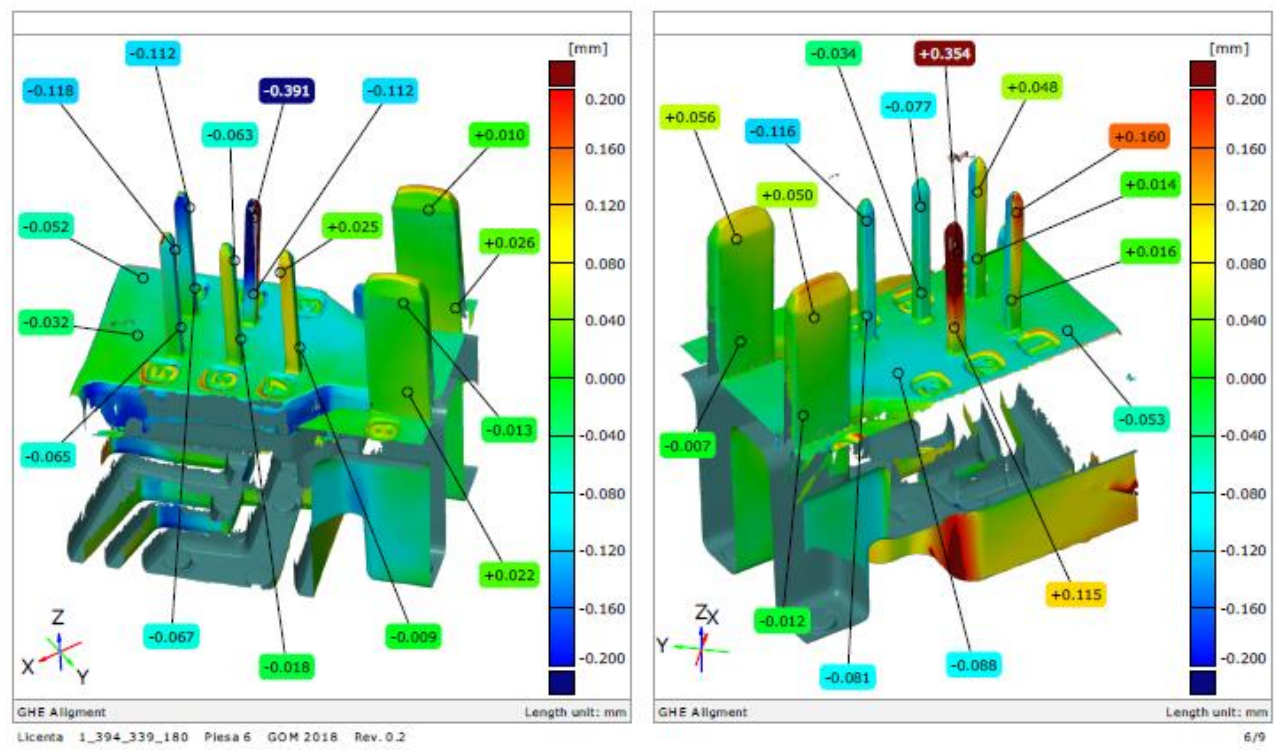

Fig. 9. Deviations between the Mesh and the CAD model in the socket area 
In order to test the first hypothesis, three other parts were measured before the assembly of the pins, by using a Werth VideoCheck IP 250 optical measuring machine. The results show that the position of the holes was deviated. The problematic region was also suggested by the MoldFlow ${ }^{\mathrm{TM}}$ simulation as it shows regions with medium predicted quality.

\section{Conclusions}

The current study analyzed the stages through which a reinforced polymer part needs to go through in order to fulfill its functional role. The reinforced material was analyzed, and flow simulations were performed in order to understand and predict the quality of the resulting part.

The part was then measured by using an optical scanner and the results compared with the CAD model of the part. The resulting part was not compliant with the requirements, making its assembly difficult and in some cases not possible.

One major flaw that was identified was with the design of the mold. In the current design, the position of the holes where the pins would be inserted is deviated leading to the difficulty in assembly with the corresponding plug.

The solution is the redesign of the mold considering the results of this study.

\section{References}

1. I. A. Popan, N. Balc, A. Popan, A. Carean, Experimental study on reverse engineering in case of composite materials cut by water jet cutting, MATEC Web Conf., 178, 03004 (2018)

2. R. Pantani, I. Coccorullo, V. Speranza, G. Titomanlio, Modeling of morphology evolution in the injection molding process of thermoplastic polymers, Prog. Polym. Sci. 30, 1185-1222 (2005)

3. E. Sabau, N. Balc, P. Bere, et al., New Materials From Waste Glass Fibre, Studia Universitatis Babes-Bolyai Chemia, 57 (4), 201-208 (2012)

4. E. Sabau, N. Balc, P. Bere, Mechanical Behavior of New Composite Materials Reinforced by Waste Glass Fibre, Conference on Interdisciplinary Research in Engineering Steps towards Breakthrough Innovation for Sustainable Development, Series: Advanced Engineering Forum, 8-9, 309-316, https://doi.org/10.4028/www.scientific.net/AEF.8-9.309 (2013),

5. Arghir, G., Bere, P.: Utilisation of composite materials in the model aircraft construction. Acta Tech. Napoc. Ser. Appl. Math. Mech. Eng. 60(1), 19-24 (2017)

6. F. Cosmi, A micro-mechanical model of the elastic properties of a short fibre reinforced polyamide, Procedia Engineering, 10, 2135-2140 (2011)

7. T. B. N. Thia, M. Moriokaa, A. Yokoyamaa, et al., Measurement of fiber orientation distribution in injection-molded short-glass-fiber composites using X-ray computed tomography, Journal of Materials Processing Technology, 219, 1-9 (2015)

8. S.G. Advani, Molding: short-fiber composites. In: Flow Processing, second ed.Wiley Encyclopedia of Composites, New York, 1-12 (2012)

9. S.G. Advani, C.L., Tucker III, The use of tensors to describe and predict fiber orientation in short fiber composites. J. Rheol. 31, 751-784 (1987) 